\title{
QUANTIFYING THE POTENTIAL IMPACT OF LAND COVER CHANGES DUE TO SEA-LEVEL RISE ON STORM SURGE ON LOWER TEXAS COAST BAYS
}

\author{
Celso M. Ferreira ${ }^{a}$, Jennifer L. Irish ${ }^{b}$ and Francisco Olivera ${ }^{c}$
}

${ }^{a}$ Assistant Professor, Department of Civil, Environmental and Infrastructure Engineering, George Mason University, 4400 University Drive, MS 6C1, Fairfax, Virginia, US, 22030 (email: cferrei3@gmu.edu).phone: 703-993-1782. (Corresponding author)

${ }^{\mathrm{b}}$ Associate Professor, Department of Civil and Environmental Engineering, Virginia Tech, 750 Drillfield Drive, 221E Patton Hall, Blacksburg, VA 24061. (email: jirish@ vt.edu) phone: 540231-2298.

${ }^{\mathrm{c}}$ Associate Professor, Department of Civil Engineering, Texas A\&M University. 3136 TAMU College Station, Texas 77843-3136. (e-mail: folivera@ civil.tamu.edu) phone: (979) 8451404.

\begin{abstract}
In this study we investigated the impacts of potential changes of land cover due to sea-level rise (SLR) on storm surge (i.e., the rise of water above normal sea level, namely mean-sea level and the astronomical tide, caused by hurricane winds and pressure) response inside bays on the lower Texas coast. We applied a hydrodynamic and wave model (ADCIRC+SWAN) forced by hurricane wind and pressure fields to quantify the importance of SLR-induced land cover changes, considering its impacts by changing bottom friction and the transfer of wind momentum to the water column, on the peak surge inside coastal bays. The SLR increments considered, 0.5 $\mathrm{m}$ to $2.0 \mathrm{~m}$, significantly impacted the surge response inside the bays. The contribution of land cover changes due to SLR to the surge response, on average, ranged from a mean surge increase
\end{abstract}


of $2 \%$ (SLR of $0.5 \mathrm{~m}$ ) to $15 \%$ (SLR of $2.0 \mathrm{~m}$ ), in addition to the SLR increments. The increase in surge response strongly depended on storm condition, with larger increases for more intense storms, and geographical location. Although land cover changes had little impact on the surge increase for SLR increments lower than $1.0 \mathrm{~m}$, intense storms resulted in surge increase of up to $10 \%$ even for SLR below $1.0 \mathrm{~m}$, but in most cases, the geometry changes were the major factor impacting the surge response due to SLR. We also found a strong relationship between changes in bottom friction and the surge response intensification; demonstrating the importance of considering land cover changes in coastal regions that are highly susceptible to SLR when planning for climate change.

Key words: hurricane storm surge, sea-level rise, land cover change, coastal bays

\section{INTRODUCTION}

Although recent studies point towards an increase in damages caused by hurricanes most likely because of climate change (e.g., Hallegatte 2012), there is still significant uncertainty regarding the impacts of climate change on hurricanes. Besides the changes in hurricanes climatology, coastal flooding will also likely increase due to future sea-level rise (SLR) (Woodruff et al. 2013). According to Church et al. (2008), in recent decades, SLR has a rate over $0.003 \mathrm{~m} / \mathrm{year}$ globally. Thus, hurricane flood risk is also expected to increase under climate change (e.g., Lin et al. 2012) and, therefore, it is critical to improve our understanding of the effects of SLR on hurricane storm surge.

A common approach to incorporate the effects of SLR on hurricane flooding is to add the SLR amount to the results of numerical simulations, made using present-day sea levels and 
present day flood statistics, of hurricane storm surges (i.e., the rise of water above the astronomical tide caused by hurricane winds and pressure). However, recently, Zhang et al. (2013) investigated the effects of SLR on storm surge from Hurricane Andrew (1992) by comparing the surge levels resulting from simulations considering a sea-level increment prior to performing numerical simulations or simply adding the same SLR increment to the model results that considered present day sea-level for Biscayne Bay, Florida. Their study demonstrates a weak non-linear effect of SLR on the surge response in the Biscayne Bay, but the authors pointed out a significantly large non-linear effect in the mainland. Although Lin et al. (2012) recognized the existence of non-linear effects of SLR on storm surge, they reported an insignificant effect for New York City. Smith et al. (2010) reported that storm surges increased from one to three meters, in addition to SLR, in wetland areas in southeast Louisiana and Irish et al. (2014) demonstrated that flood elevations were 15 to $60 \%$ higher due to SLR when recreating hurricane Katrina under c. 1900 climate and sea level conditions. Ratcliff and Smith (2011) reported significant storm surge variances due to the effects of SLR in numerical simulations for Chesapeake Bay, specifically in marsh areas and locations protected by surrounding topography. Mousavi et al. (2011) found that, although the effects of SLR on storm surge variance was negligible along the coast, changes in the surge response inside coastal bays are significant. Atkinson et al. (2012) evaluated the effects of storm conditions and SLR on the surge response along the entire Texas coast including variation on coastal landscapes, which also demonstrates that the surge response to SLR varies by storm scenario and geographical location. These studies all point towards the fact that the linear superposition of SLR and storm-induced surge leads to an underestimation of flooding. 
Although the non-linear effect of SLR on surge has been demonstrated, the effect of land cover change due to SLR on the surge increase has not been fully explored. The effects of SLR on coastal vegetation are extremely complex and still a subject of active research (e.g., Alongi 2007, Chu-Agor et al. 2011, Craft et al. 2009, Galbraith et al. 2002 and Hagen et al. 2012). Several studies have incorporated changes in land cover when evaluating the impacts of SLR on surge (e.g., Smith et al. 2010 and Zhang et al. 2013) and also the potential impact of wetland degradation on storm surge and wetland restoration to reduce storm surge (e.g., Wamsley et al. 2010). Bilskie et al. (2014) explored the effects of historical changes in land cover (1960 to 2005 ) and future changes (2005 to 2050) on hurricane surge under SLR (intervals up to $\sim 0.5 \mathrm{~m}$ ). Their study in the Mississippi and Alabama coast demonstrated up to $70 \%$ increase in surge levels for Hurricane Katrina in some regions. Although Atkinson et al. (2012) recently indicated that the effect of land cover change due to SLR is negligible based on results from two storms on Galveston Bay, our hypothesis is that potential changes of the land surface due to SLR can significantly affect the surge response, especially in coastal bays, and is highly dependent on storm conditions.

In this article, we systematically quantify the impact of land cover change by comparing the results of numerical simulations of hurricane storm surge with and without incorporating changes in land cover due to SLR in coastal bays in the Texas lower coast. Our novel contribution is the systematic quantification of the importance of the changes in land cover due to the non-linear effects of SLR on hurricane storm surge response.

\section{METHODOLOGY}

\subsection{Coastal bays in Texas}


The Gulf of Mexico coastline is prone to frequent major hurricane events (e.g. Hurricane Katrina [2005], Ike [2008], Isaac [2012]). We concentrate this study in Corpus Christi Bay, Nueces Bay and Oso Bay (Figure 1). These bays are separated from the open coast by a narrow barrier island and are connected to the ocean only by the Aransas Pass. This region is home of the city of Corpus Christi, with a population of approximately 300,000 people, and is the location of a Naval Air Station and the fifth largest port in the nation, the Port of Corpus Christi. The coastal vegetation in the area is mainly composed of salt, brackish and fresh marshes, tidal flats and seagrass beds (Tremblay et al. 2008).

\subsection{Numerical modeling}

We used the two-dimensional depth-integrated version of the Advanced Circulation (ADCIRC) model coupled with the spectral wave model SWAN (Dietrich et al. 2011) to simulate hurricane storm surge. ADCIRC (Luettich and Westerink 2004) is a finite-element, shallow water model that calculates water levels and currents at a range of scales, and is widely used for storm surge modeling (e.g., Bunya et al. 2010, Dietrich et al. 2011, Ebersole et al. 2010 and Westerink et al. 2008). SWAN is a third generation spectral wave model that computes random, short-crested wind-generated waves, and wave transformation in nearshore and inland waters (Booij et al. 1999). The coupled version of ADCIRC and SWAN (Dietrich et al. 2011) uses the same unstructured finite element numerical mesh for both models. We used a high-resolution computational mesh for the study area (Ferreira et al. 2014) based on a regional scale validated mesh for the Texas coast (Kennedy et al. 2011; Dawson et al. 2011). The numerical mesh has 1.3 million nodes and 2.5 million elements with resolution up to $30 \mathrm{~m}$ inside the study area. This model setup was validated in several locations, exhibiting an $\mathrm{R}^{2}$ of 0.96 when compared to the 
regional scale mesh (Ferreira et al. 2014). Tidal forcing was neglected due to its small amplitude in the study area (e.g., $0.17 \mathrm{~m}$ at the National Oceanic and Atmospheric Administration [NOAA] station Port Ingleside in Corpus Christi Bay). River inflows were also neglected in order to simplify the analyses.

Hurricane wind and pressure fields were created using a steady-state dynamic vortex model, based on the equation of horizontal momentum, vertically-averaged through the depth of the planetary boundary layer (PBL) (Thompson and Cardone 1996). This PBL model used sixhourly meteorological conditions (hurricane central pressure, radius of maximum speeds, storm track, Holland B parameter, and storm forward speed) to develop 15-min wind and pressure fields. A review of the historical hurricane record (NOAA 2012a) identified Hurricanes Bret (1999), Beulah (1967), Allen (1980) and Carla (1961) as events directly impacting the study region. We assume these storms characterize typical hurricane meteorological conditions for the study area. Based on these storms, we selected key meteorological hurricane parameters (central pressure, forward speed and radius to maximum wind) to develop nine hypothetical storms. The hypothetical storms represent three landfall locations (Figure 1), considering two maximum forward speeds (11 and $37 \mathrm{~km} / \mathrm{h}$ ), two maximum central pressures (930 and $960 \mathrm{mb}$ ) and one hurricane radius to maximum winds $(31.5 \mathrm{~km}$ ) (Table 1). These values represent common hurricane conditions for the study area (Resio et al. 2007). Note that the wind and pressure fields applied to each SLR are the same based on the selected storm characteristics from Table 1.

\subsection{Sea-level rise scenarios}

Church et al. (2008) demonstrated an increase in the rate of SLR based on gage data and remote sensing over the last century. Current research arguably points towards a probable increased rate 
of SLR during this century (e.g., Nichols and Cazenave 2010). Based on several studies (e.g., Jevrejeva et al. 2010 [0.60 1.80 m]; Rahmstorf 2007 [0.50 1.40 m]; International Panel on Climate Change 2007 [0.20 0.60]; National Research Council 1987 [0.50 1.50 m]), the U.S. Army Corps of Engineers (USACE) recommends considering an SLR upper bound of two meters for 2100 in civil work programs (USACE 2011). More specific to our study area, the observed SLR rate, based on the record from 1948 to 2006 at the Rockport TX station, is $0.00516(+/-0.00067) \mathrm{m} / \mathrm{year}$ (NOAA 2012b) and subsidence rates in the region are estimated to be $0.0029 \mathrm{~m} /$ year (Frey et al. 2010) which using a linear extrapolation (note that even higher rates could be expected due to non-linear rise in the SLR rates) would result in approximately $0.80 \mathrm{~m}$ of SLR by 2100 in the study area. To cover the full range of possible SLR scenarios, we used $0.50,1.00,1.50$ and $2.00 \mathrm{~m}$ in our analysis.

\subsection{Impacts of sea-level rise on topography}

Morphological responses of barrier islands to SLR are extremely complex (Ashton et al. 2007) and strongly related to the rate and acceleration of SLR (Titus 1990). Irish et al. (2010) discussed that, although the barrier islands in Corpus Christi Bay were able to form due to a slow SLR rate for the past 3000 to 7000 years, their future morphological response to SLR would greatly vary according to the SLR rate (e.g., SLR exceeding 0.1-0.2 m/year would cause them to break up and drown). On the other hand, with slow rates of SLR, the barrier island could became stable or migrate landward. Therefore, it is difficult to predict the exact response of barrier islands to SLR. To simplify the analysis, the effect of SLR is taken into account in the model by increasing the base water level above the current MSL (2000s) for the entire model domain as an initial condition for the simulation. Therefore, we are statically increasing the water level and not 
including any morphological changes to the coastal morphology due to SLR. However, the shoreline is changing with SLR (Figure 2) as the sea-level is rising (bathtub approach). In this simplified approach, a SLR of up to $1.0 \mathrm{~m}$ would not greatly affect the barrier island as it is today; however, SLRs greater than $1.0 \mathrm{~m}$ would significantly impact the shoreline and the barrier island. The barrier island would breach in several locations with $1.5 \mathrm{~m}$ of SLR and would almost be completely submerged for $2.0 \mathrm{~m}$. We expect these effects to have a significant impact on the surge in the bays as the open coast surge can freely propagate inside.

\subsection{Land cover changes}

Estimating the impacts of SLR on wetlands is still subject of current research (e.g., Hagen et al. 2012) and although tools such as the Sea Level Affecting Marshes Model (SLAMM 5) have been widely used to explore the vulnerability of coastal habitats to SLR (e.g. Chu-Agor et al. 2011) predicting future land cover for coastal areas is still complex and uncertain. For example, Michener et al. (1997) discusses how SLR is expected to cause drowning and inland migration of coastal wetlands. To explore potential effects of land cover changes due to SLR on storm surge, we applied the criterion proposed by Smith et al. (2010) to relate the effects of SLR to spatial changes in coastal vegetation by estimating changes to bottom friction and wind forcing mechanisms. We expect that such land cover changes will directly affect surge generation and propagation inside the bays. Wetlands and other coastal vegetation are represented in the numerical models through their influence on the forcing and dissipation mechanisms of hurricane storm surge. Vegetation impedes momentum transmitted to the water column by winds and increases frictional drag; both of these effects are taken into account in the computational models. The frictional resistance at the sea bottom is accounted for by using a non-linear bottom 
drag coefficient related to land cover surface roughness. Here, we calculate the dimensionless friction coefficient $\left(\mathrm{C}_{\mathrm{f}}\right)$ based on the Manning's $n(n)$ parameter using (Eq. 1):

$$
C_{f}=g * \frac{n^{2}}{h^{(1 / 3)}}
$$

where $g\left[\mathrm{~m}^{2} / \mathrm{s}\right]$ is the acceleration due to gravity and $h[\mathrm{~m}]$ is water depth. The friction coefficient is incorporated into the bottom shear stress $\left(\overrightarrow{\tau_{b}}\right)$ formulation by (Eq. 2$)$

$$
\overrightarrow{\tau_{b}}=\frac{C_{f} \vec{U}|\vec{U}|}{h}
$$

where $\vec{U}$ is the depth-averaged horizontal velocity vector $[\mathrm{m} / \mathrm{s}]$. To characterize existing coastal wetland types and define their spatial distribution within the study area, we used the National Wetlands Inventory (NWI) (U.S. Fish and Wildlife Service, 2012). To specify the spatially variable land cover parameters, we used the methods of Atkinson et al. (2011), which have been employed and validated in a number of surge modeling studies (e.g., Dietrich et al. 2011, Leuttich and Westerink 2004 and Tsihrintz and Madiedo 2000).

The static water depth under a given SLR scenario is spatially calculated using the National Elevation Dataset (NED) (USGS 2012) with a resolution of $30 \mathrm{~m}$. The impacts of SLR on coastal vegetation and therefore changes in bottom friction and the quantity of wind momentum transmitted to the water column are estimated based on the criteria defined by Smith et al. (2010) and presented in Appendix A. As previously stated, these impacts are extremely complex and uncertain; therefore this method tries to quantify these changes based on a reduced complexity approach by systematically changing bottom friction parameters and amount of wind transmitted to the water column based on assumptions such as vegetation drowning and migration. The bottom friction and the amount of wind transmitted to the water column are 
changed spatially by comparing the future Mean High Water (MHW) and Mean Low Water (MLW) to the current topography and coastal vegetation. If a given location that was previously dry has become below the MLW, the vegetation cover is removed and substituted to represent mud/sand. If a given location that was previously dry has become in the range of the MLW and MHW the land cover is adjusted to represent coastal vegetation. The MLH and MHW are calculated as a constant water surface for the for each SLR scenario by adding/subtracting the assumed tidal amplitude $(10 \mathrm{~cm})$ (NOAA 2012b). A new set of geospatial parameter files is produced by comparing the land elevation to the MHW and MLW at each cell for a given SLR scenario, by changing the spatial parameters accordingly.

\subsection{Impacts of sea-level rise on storm surge}

Resio and Westerink (2008) demonstrate that the storm surge is strongly dependent on water depth and continental shelf width, as well as forcing and dissipation mechanisms. Therefore, we expect that the impacts of SLR on the surge response for coastal bays will be related to alterations in the surge forcing and dissipation mechanisms, and to geometrical changes in coastal bays. The geometric changes are mostly related to water depth changes (MSL increase with SLR) and an increase in the bay water surface area, which increases the local wind fetch. Here, we define storm surge as the increment of water level above MSL caused by meteorological effects only:

$\zeta=h-M S L$

where $\zeta$ is the surge and $M S L$ is the mean sea-level at the time of interest. Ignoring the influence of any land cover changes, we expect surges to decrease with increasing water depth, and to 
increase with increasing wind fetch as demonstrated by Resio and Westerink (2008) from the shallow-water equations momentum balance:

$\zeta \propto\left(\frac{\tau_{s}}{g h}\right) W_{f e t c h}$

where $\tau_{s}$ is free-surface shear stress, $g$ is acceleration due to gravity and $W_{\text {fetch }}$ is wind fetch. Thus, competing processes (SLR is expected to cause higher depths at the shoreline and also provide larger wind fetch areas due to the extended water surface areas) influence local surge generation in coastal bays as SLR. However, land cover changes are also expected to impact the frictional drag at the sea bottom and changes in the transfer of momentum to the water column by the wind.

For this study, we calculate the surge anomaly $\left(\phi_{s}\right)$ for each storm condition due to SLR as:

$\Phi s(m)=\frac{\sum_{1}^{j}\left(\zeta_{i, s, \Delta_{S L R}}-\zeta_{i, s, M S L_{\text {turrenday }}}-\Delta_{S L R}\right)}{j}$

$\Phi s(\%)=\frac{\sum_{1}^{j} \frac{\left(\zeta_{i, s, \Delta_{S L R}}-\zeta_{i, s, M S L_{\text {uurrenday }}}-\Delta_{S L R}\right)}{\zeta_{i, s, M S L_{\text {turrenday }}}}}{j} * 100$

Where $m$ is meters, $\%$ is the percent change, $j$ is the number of recording points (i.e., location where we are recording water levels within the bay), $i$ is the location of recording point, $s$ is the storm condition, $\zeta_{i, s, \Delta_{S L R}}$ is the surge estimated under SLR, $\zeta_{i, s, M S L_{\text {currentay }}}$ is the surge estimated under current-day sea level $\left(M S L_{\text {currentday }}\right)$, and $\Delta_{S L R}$ is the SLR increment. The overall impact of SLR on surge $(\bar{\Phi})$ is calculated by averaging $\phi_{\mathrm{s}}$ : 
$\bar{\Phi}=\frac{\sum_{1}^{s} \Phi s}{s}$

To explore the specific impacts of land cover changes due to SLR on surge, the simulations are repeated with and without including changes in bottom friction and forcing mechanism in the numerical model as described in section 2.5 . The surge anomaly due to land cover $\left(\phi_{\text {s-landcover }}\right)$ is calculated by:

$\Phi_{s-l a n d c o v e r}(m)=\frac{\sum_{1}^{j}\left(\zeta_{i, s, \Delta_{S L R}}-\zeta_{i, s, M S L_{\text {uurentay }}}-\Delta_{S L R}\right)-\left(\zeta_{i, s, \Delta_{S L R}, \text { no-landcover }}-\zeta_{i, s, M S L_{\text {Lurrenday }}}-\Delta_{S L R}\right)}{j}$

$\Phi_{\text {s-landcover }}(\%)=\frac{\sum_{1}^{j} \frac{\left(\zeta_{i, s, \Delta_{S L R}}-\zeta_{i, s, M S L_{\text {currenday }}}-\Delta_{S L R}\right)-\left(\zeta_{i, s, \Delta_{S L R}, \text { no-landcover }}-\zeta_{i, s, M S L_{\text {currentay }}}-\Delta_{S L R}\right)}{\zeta_{i, s, M S L_{\text {currenday }}}}}{j} * 100$

where $\zeta_{i, s, \Delta_{S L R}, n o-l a n d c o v e r}$ is the surge estimated under SLR neglecting land cover effects. The overall impact of land cover changes due to SLR on surge $\left(\overline{\Phi_{\text {landcover }}}\right)$ is calculated by:

$\overline{\Phi_{\text {landcover }}}=\frac{\sum_{1}^{s} \Phi_{s-l a n d c o v e r}}{s}$

We recorded simulated water levels for 215 recording points along the study area representing the coastal bays and its margins (Appendix B): Corpus Christi Bay (54), Nueces Bay (40), Oso Bay (36), the margins of Corpus Christi Bay (55), the margins of Nueces Bay (30).

\section{RESULTS AND DISCUSSION}

3.1 Effects of sea-level rise on bottom friction and wind momentum transfer to the water column parameters 
For SLR values of $0.5,1.0,1.5$ and $2.0 \mathrm{~m}$, the inundated areas due to static SLR alone were 700, 1000, 2500 and $3000 \mathrm{~km}^{2}$, respectively, in our study area. Although the $1.0 \mathrm{~m}$ SLR scenario did not significantly affect the bottom friction (i.e., mean Manning's $n$ ), higher SLR amounts did have a significant impact (Figure 3 ). In fact, the permanent inundation of coastal vegetation in the study area resulted in a mean Manning's $n$ reduction from 0.055 at present day to 0.040 for $2.0 \mathrm{~m}$ of SLR. The areas that currently provided wind shield were also affected by SLR greater than $1.0 \mathrm{~m}$, and were reduced by up to $150 \mathrm{~km}^{2}$ for $2.0 \mathrm{~m}$ of SLR. While for $0.5 \mathrm{~m}$ of SLR, the changes in Manning's $n$ are mostly less than 0.030 and concentrated in the wetland areas behind the barrier islands and around Aransas Pass; for $2.0 \mathrm{~m}$ of SLR, the changes in Manning's $n$ are over 0.050 in almost all the marginal areas, and the barrier island is submerged in several locations (Figure 4).

\subsection{Overall impact of SLR on surge}

We performed an Analysis of Variance (ANOVA) to verify the existence of a significant effect of SLR on the mean maximum surge at the 215 recording points. The null hypothesis $\left(\boldsymbol{H}_{\boldsymbol{o}}\right)$ is that the mean maximum surge does not change for the same meteorological conditions $\left(\boldsymbol{H}_{\boldsymbol{o}}: \boldsymbol{\mu}_{\text {present }}=\right.$ $\boldsymbol{\mu}_{s l r} 0.5=\boldsymbol{\mu}_{s l r 1.0}=\boldsymbol{\mu}_{s l r 1.5}=\boldsymbol{\mu}_{s l r 2.0}$ ), and the null hypothesis is rejected if at least one mean maximum surge is significantly different: $p$ value $<0.05$ (95\% confidence interval) using an $F$-test. From this analysis, within the bays, the SLR significantly impacts mean maximum surge ( $p$ values lower than 0.05, see Appendix C). However, the analysis also shows that SLR does not have a significant impact on storm surge at open coast stations ( $p$ values close to one, see Appendix C), in alignment with the findings of Mousavi et al. (2011) and Atkinson et al. (2012) for the same study region, Lin (2012) for the New York coast and Zhang et al. (2013) for the Florida coast. 
Our results also demonstrate that the impacts of SLR on surge are highly dependent on storm conditions and specific locations within the study area. These findings are also in direct accordance with the findings of Atkinson et al. (2012) for the Texas coast. In our case, for example, the null hypothesis could not be rejected ( $p$ values greater than 0.05 , see Appendix C) at Oso Bay and Nueces Bays Margins for storm C-11-960. We hypothesize that the combination of its weaker central pressure, slow forward speed and its distant landfall location were insufficient to make the SLR effects felt in Oso Bay (relatively very small Bay) and at the margins of Nueces Bay. Note that a similar landfall location and central pressure with a relative faster forward speed (storm C-37-960) were sufficient to significantly impact the surge response at the same locations. Overall, the resulting $\phi_{s}(\mathrm{~m})($ Eq. 5) is positive and increases with SLR. The SLR scenario of $0.5 \mathrm{~m}$ resulted in a mean surge increase of $0.13 \mathrm{~m}$, SLR of $1.0 \mathrm{~m}$ lead to a mean surge increase of $0.27 \mathrm{~m}$, SLR of $1.5 \mathrm{~m}$ occasioned a mean surge increase of $0.57 \mathrm{~m}$ and the SLR scenario of $2 \mathrm{~m}$ resulted in a mean surge increase of $0.76 \mathrm{~m}$ (Figure 5). The standard deviation of the mean surge anomaly also increases for each SLR scenario from $0.18 \mathrm{~m}$ at $0.5 \mathrm{~m}$ of SLR to $0.49 \mathrm{~m}$ at $2.0 \mathrm{~m}$ of SLR.

\subsection{Impact of land cover changes due to sea-level rise on surge}

Uncertainties in peak surge due to land cover specification can reach up to $7 \%$ of the predicted surge value in coastal bays (Ferreira et al. 2014b). Following the small rates of change of Manning's $n$ and potential reduction of wind momentum transferred to the water column by vegetation for SLR scenarios of $1.0 \mathrm{~m}$ or less, the contribution of changes in the land cover due to SLR to the mean maximum surge anomaly is no more than $0.05 \mathrm{~m}$ when averaging all storm simulations (Eq. 10); representing a peak surge increase of $2 \%(\mathrm{std}=7 \%)$ for $0.5 \mathrm{~m}$ of SLR and 
$3 \%(\mathrm{std}=7 \%)$ for $1.0 \mathrm{~m}$ of SLR inside the bays. These are in agreement with the observations presented in Atkinson et al. (2012) and could be considered relatively small when in perspective of known surge modeling uncertainties due to land cover. However, note that although the average anomaly for SLR intervals of $1.0 \mathrm{~m}$ or less is significantly small, when incorporating the standard deviation the contribution of land cover changes can add up to a $10 \%$ increase in the surge anomaly. The most significant increase in the mean maximum surge due to land cover changes from SLR is for SLR between 1.0 to $1.5 \mathrm{~m}$, resulting in an average surge increase from 0.10 to $0.27 \mathrm{~m}$ representing a $13 \%(\mathrm{std}=7 \%)$ surge increase. In this interval, we also identified a greater reduction in Manning's $n$ and in the potential of momentum transfer from the wind to the water column areas, which is in accordance to the findings from Smith et al. (2010), that verified significant surge increases with SLR in areas where the bottom friction (Manning's $n$ ) was significantly reduced by SLR in the Louisiana Coast. For SLR scenarios above $1.5 \mathrm{~m}$ the overall mean maximum surge increase is $0.20 \mathrm{~m}$. When considering $2.0 \mathrm{~m}$ of SLR, although the mean maximum surge did not increase significantly, for some storm conditions, the mean maximum surge considering all locations was up to $0.35 \mathrm{~m}$ above the surge levels for simulations with similar SLR rates and land cover for present day conditions representing 15\% (std=6\%) increase from the current MSL surges (Figure 6).

With respect to storm conditions, we found that the type of storm condition significantly impacted the variation of the surge increase from SLR for the same location. The most intense and faster storm (i.e., $V f: 37.0 \mathrm{~km} / \mathrm{h} ; C p: 930 \mathrm{mb}$ ) generated surge increases of up to almost 1.0 $\mathrm{m}$ on selected locations leading to the conclusion that storm intensity played an important role in increasing the surge anomalies. We hypothesize that this is directly related to the increased quantity of momentum transmitted to the water column as a result of degraded wetlands under 
SLR. These effects can increase the surge by $10 \%$ and is especially important when considering SLR scenarios below $1.0 \mathrm{~m}$, where the average impact of land cover change effects could be overshadowed by the impact of geometrical changes. Although the surge anomaly is very sensitive to the storm intensity, the weaker but faster storm (i.e., $V f: 37.0 \mathrm{~km} / \mathrm{h} ; C p: 960 \mathrm{mb}$ ) also resulted in above average surge increases for two tracks (B and C). The surge generated by the weaker and slower storms ( $V f: 11.0 \mathrm{~km} / \mathrm{h} ; C p: 960 \mathrm{mb}$ ) were less sensitive to SLR and resulted in surge increases of less than $0.4 \mathrm{~m}$ for the highest SLR scenario considered. These results also might demonstrate why Atkinson et al. (2012) could have encountered insignificant impacts of land cover changes to their surge results.

The surge anomaly due to land cover changes for the study area can be reasonably described by the average changes in bottom friction due to SLR. These results demonstrate and quantify the impact of land cover changes to the overall surge increase due to SLR that has already been well documented in the literature. For example, Zhang et al. (2013) estimated surge increases of 22-24\% for SLR up to $1.05 \mathrm{~m}$ for the mainland of Biscayne Bay; here, we demonstrated that for a SLR of $1.0 \mathrm{~m}$ we could expected land cover effects to increase surge by $\sim 3-10 \%$, demonstrating the importance of correctly incorporating changes in land cover when estimating the impacts of SLR on surge.

\subsection{Geographical effects on surge anomaly}

With respect to the geographical location of the surge anomalies, as expected, the variations in surge due to land cover changes are highly correlated to the changes in the bottom friction and the forcing mechanisms. For example, Figure 7 shows the surge anomaly results for an intense storm on track B (i.e., $V f: 37.0 \mathrm{~km} / \mathrm{h}$; $C p: 930 \mathrm{mb}$ ) where we can see the relative lower surge 
anomalies in Oso Bay and Nueces Bay and higher anomalies in Corpus Christi Bay reflecting the bottom friction changes (Figure 4) behind the barrier islands. The increase in changes to bottom friction and forcing mechanisms with SLR also triggered the surge anomalies to spatially expand with SLR propagating in Oso Bay and Nueces Bay for SLR of 2.0 meters. Also, although most locations follow the general trend of a mean maximum surge increase with SLR, at some locations there is no surge increase at all, with the surge anomaly very close to zero. Within the bays, Oso Bay presented the lowest rate of increase in mean maximum surge, with values up to 0.30 and $0.80 \mathrm{~m}$ for SLRs of 1.0 and $2.0 \mathrm{~m}$, respectively; most likely due to its small size in comparison to the other bays. Conversely, positive surge anomalies reached up to $3 \mathrm{~m}$ in selected locations along Corpus and Nueces Bays. We also found relatively small surge anomalies at specific sides of the bays, strongly related to the relative position of the bay with respect to landfall location (left side of landfall location), in accordance to the findings presented by Mousavi et al. (2011) and Zhang et al. (2013).

\section{SUMMARY AND CONCLUSIONS}

We analyzed the potential impact of land cover changes due to SLR on hurricane storm surge for bays in the lower Texas coast. It has been previously demonstrated that SLR will increase hurricane storm surge; but the impact that potential changes in land cover due to SLR would have on the surge increase has yet to be explored. The effects of land cover changes due to SLR were quantified by the changes in the frictional drag and the changes in momentum transfer from the wind to the water column. The land cover contribution to the surge increase due to SLR is quantified by the difference in model results with and without predicted land cover changes. 
The results demonstrated that, although the mean maximum surge significantly increases with SLR in coastal bays for SLR of up to $1.0 \mathrm{~m}$, the contribution of land cover is on average only $\sim 3 \%$ of the original surge. The variability of the surge response is also greatly affected by the storm meteorological conditions (greater increase for more intense storms) and the location of interest (greater increase for larger bays). These effects were noteworthy to consider as the land cover change contribution could be as high as $10 \%$ of the original surge for intense storms when the SLR interval was less than $1.0 \mathrm{~m}$. For SLR intervals from $1.0 \mathrm{~m}$ to $2.0 \mathrm{~m}$ the changes in land cover drastically impacted the surge anomaly, by as much as $20 \%$.

The major limitations of this study consist of the modeling approach adopted to predict future land cover and topo-bathymetric changes due to SLR, which did not fully account for the complexity of these processes. Although the bath-tub approach is unrealistic to predict SLR changes to coastal geomorphology, it serves as a base case test-bed to explore the impact of land cover changes on surge. On the other hand, the over-simplified model to estimate land cover changes due to SLR has a direct impact on the predicted surge anomalies magnitude. Yet, this simplified land cover change model serves as an indicator of the importance of incorporating land cover changes due to SLR when modeling hurricane storm surge under future climate change scenarios. Future studies might incorporate more accurate land cover change models to better quantify these impacts on the surge response on a location specific basins.

Although the values and relationships presented are strongly related to local environment characteristics, it offers guidance for climate change planning and research and demonstrates the importance of incorporating SLR when simulating coastal bay storm surges under climate change. For example, local conditions such as topo-bathymetry play a major role in quantifying these impacts and the relationships presented here can differ significantly for different regions. 
However, we demonstrate that, for certain storm conditions and low SLR rates, we can safely neglect the impact of land cover changes due to SLR on the surge increase. Nevertheless, the land cover contribution to the surge anomalies for SLR scenarios of $1 \mathrm{~m}$ or more, or for intense storms when SLR is below $1 \mathrm{~m}$, can significantly impact flood estimations; for these cases the influence of land cover changes should not be omitted from the surge analysis. We also demonstrate the high correlation between changes in bottom friction and surge increases, indicating that these factors should be specially considered in regions where land cover is highly susceptible to changes due to SLR.

\section{ACKNOWLEDGEMENTS}

This research was funded by the Texas General Land Office via a Grant/Cooperative Agreement from the NOAA (Grant No. 10-051-000-3747); the National Sea Grant College Program of the U.S. Department of Commerce's NOAA (Grant No. NA10OAR4170099); and the Office of Science (BER) U.S. Department of Energy [DOE] (Grant No. DE-FG02-08ER64644). The views expressed herein are those of the authors and do not necessarily reflect views of NOAA, DOE or any sub agencies. The use of trade names does not constitute an endorsement in the use of these products by the U.S. Government. The authors thank Oceanweather, Inc., for allowing us to use their planetary boundary layer model. The authors acknowledge the Texas A\&M Supercomputing Facility (http://sc.tamu.edu/), the Texas Advanced Computing Center (TACC) at The University of Texas at Austin and the CU-CSDMS High-Performance Computing Cluster for providing HPC computing resources useful in conducting the research reported in this paper. This work also used the Extreme Science and Engineering Discovery Environment (XSEDE), which is supported by National Science Foundation grant number OCI-1053575. 


\section{REFERENCES}

Alongi, D. M. (2008) "Mangrove forests: Resilience, protection from tsunamis, and responses to global climate change." Estuarine, Coastal and Shelf Science, (76), 1-13.

Ashton, A. D., Donnelly, J. P. and Evans, R. L. (2007) A discussion of the potential impacts of climate change on the shorelines of the Northeastern USA. Mitigation Adaptation Strategies Global Change. DOI 10.1007/s11027-007-9124-3

Atkinson, J., H. Roberts, S.C. Hagen, S. Zhou, P. Bacopoulos, S. Medeiros, J. Weishampel and Z. Cobell (2011) "Deriving Frictional Parameters and Performing Historical Validation for an ADCIRC storm surge model of the Florida gulf coast." Florida Watershed Journal, 4 (2), 22-27. Atkinson, J.; Smith, J. M.; Bender, C. (2012) Sea Level Effects on Storm Surge and Nearshore Waves on the Texas Coast: Influence of Landscape and Storm Characteristics. Journal of Waterway, Port , Coastal and Ocean Engineering DOI:10.1061/(ASCE)ww.1943-5460.0000187 Bilskie, M., Hagen, S., Medeiros, S., and Passeri, D. (2014). "Dynamics of sea level rise and coastal flooding on a changing landscape." Geophysical Research Letters. Online publication date: 1-Feb-2014.

Bjarnadottir, S.; Li, Y. and Stewart, M. G. (2011). "Social vulnerability index for coastal communities at risk to hurricane hazard and a changing climate." Natural Hazards, 59(2), 10551075.

Booij, N. Ris, R. C. and Holthuijsen, L. H. (1999) A third generation wave model for coastal regions. Model Description and Validation. Journal of Geophysical Research 104:7649-7666 Bunya, S., Dietrich, J., Westerink, J., Ebersole, B., Smith, J., Atkinson, J., Jensen, R., Resio, D., Luettich, R., Dawson, C., Cardone, V., Cox, A., Powell, M., Westerink, H., and Roberts, H. 
(2010). "A High-Resolution Coupled Riverine Flow, Tide, Wind, Wind Wave, and Storm Surge Model for Southern Louisiana and Mississippi. Part I: Model Development and Validation." Monthly Weather Review, 345-377.

Chu-Agor, M., Munoz-Carpena, R., Kiker, G., Emanuelsson, A., and Linkov, I. (2011). "Exploring vulnerability of coastal habitats to sea level rise through global sensitivity and uncertainty analyses." Environmental Modelling \& Software, 593-604.

Church, J.; White, N.; Aarup, T.; Wilson, W. S.; Woodworth, P.L.; Domingues, C.M.; Hunter, J.R. and Lambeck, K. (2008). "Understanding global sea levels: past, present and future." Sustainability Science, 3(1), 9-22.

Craft, C., Clough, J., Ehman, J., Joye, S., Park, R., Pennings, S., Guo, H., and Machmuller, M. (2009). "Forecasting the effects of accelerated sea-level rise on tidal marsh ecosystem services." Frontiers in Ecology and the Environment, 73-78.

Dawson, C.; Kubatko E. J.; Westerink J. J.; Trahan, C.; Mirabito, C. ;Michoski, C.; Panda, N. (2011). Discontinuous Galerkin Methods for Modeling Hurricane Storm Surge. Advances in Water Resources, 34, 1165-1176.

Dietrich, J., Zijlema, M., Westerink, J., Holthuijsen, L., Dawson, C., Luettich, R., Jensen, R., Smith, J., Stelling, G., and Stone, G. (2011). "Modeling hurricane waves and storm surge using integrally-coupled, scalable computations." Coastal Engineering, 45-65.

Ebersole, B., Westerink, J., Bunya, S., Dietrich, J., and Cialone, M. (2010). "Development of storm surge which led to flooding in St. Bernard Polder during Hurricane Katrina." Ocean Engineering, 91-103.

Ferreira, C. M.; Irish, J.; Olivera, F (2014) “ArcStormSurge: Integrating GIS and Hurricane Storm Surge". Journal of the American Water resources Association 50(1)219-233 
Ferreira, C. M.; Irish, J.; Olivera, F (2014b) "Uncertainty in hurricane surge simulation due to land cover specification" Journal of Geophysical Research - Oceans, 119

Frey, A., Olivera, F., Irish, J., Dunkin, L., Kaihatu, J., Ferreira, C., and Edge, B. (2010). "Potential impact of climate change on hurricane flooding inundation, population affected and property damages in Corpus Christi." Journal of the American Water Resources Association, 1049-1059.

Galbraith, H., Jones, R., Park, R., Clough, J., Herrod-Julius, S., Harrington, B., and Page, G. (2002). "Global climate change and sea level rise: Potential losses of intertidal habitat for shorebirds." Waterbirds, 173-183.

Hagen, S., Morris, J., Bacopoulos, P., and Weishampel, J. (2013). ”Sea-Level Rise Impact on a Salt Marsh System of the Lower St. Johns River.” J. Waterway, Port, Coastal, Ocean Eng., 139(2), 118-125.

Hallegatte, S. (2012). "Economics: The rising costs of hurricanes." Nature Climate Change, 2(3), $148-149$

Intergovernmental Panel on Climate Change, (2007) Climate Change 2007: The Physical Science Basis. Contribution of Working Group I to the Fourth Assessment Report of the Intergovernmental Panel on Climate Change [Solomon, S., D. Qin, M. Manning, Z. Chen, M. Marquis, K.B. Averyt, M.Tignor and H.L. Miller (eds.)]. Cambridge University Press, Cambridge, United Kingdom and New York, New York, USA.

Irish, J L.; Sleath, A.; Cialone, M. A.; Knutson, T. R.; and Jensen, R. E. (2014) "Simulations of Hurricane Katrina (2005) under sea level and climate conditions for 1900.” Climatic Change, 122. DOI:10.1007/s10584-013-1011-1 
Irish, J. L.; Frey, A. E.; Rosati, J. D.; Olivera, F.; Dunkin, L. M.; Kaihatu, J. M.; Ferreira C. M. and Edge, B. L. (2010) Potential Implications of global warming and barrier island degradation on future hurricane inundation, Ocean and Coastal Management, Vol. 53, 645-657.

Jevrejeva, S., J. C. Moore, and A. Grinsted (2010) "How will sea level respond to changes in natural and anthropogenic forcings by 2100?” Geophys. Res. Lett., 37, L07703.

Kennedy, A. B.; Gravois, U.; Zachry, B. C.; Westerink, J. J.; Hope, M. E.; Dietrich, J. C.;

Powell, M. D.; Cox, A. T.; Luettich Jr., R. A.; Dean, R. G. (2011). Origin of the Hurricane Ike Forerunner Surge. Geophysical Research Letters, 38, L08608.

Lin, N.; Emanuel, K.; Oppenheimer, M. and Vanmarcke, E. (2012). "Physically based assessment of hurricane surge threat under climate change." Nature Climate Change.

Luettich, R. and Westerink, J. (2004). Formulation and numerical implementation of a 2D/3D ADCIRC Finite Element Model Version 4.46. http://adcirc.org/adcirc_theory_2004_12_08.pdf, accessed 13 November 2010

Michener, W. K.; Blood, E. R.; Bildstein, K. L.; Btinson, M. M. and Gardner, L R. (1997) "Climate change, hurricanes and tropical storms, and rising sea level in coastal wetlands." Ecological Applications, (7),770-801

Mousavi, M., Irish, J., Frey, A., Olivera, F., and Edge, B. (2011). "Global warming and hurricanes: the potential impact of hurricane intensification and sea level rise on coastal flooding." Climatic Change, 575-597.

National Oceanic and Atmospheric Administration (2012a) Atlantic basin hurricane database (HURDAT). http://www.aoml.noaa.gov/hrd/hurdat/ Accessed 08 July 2012.

National Oceanic and Atmospheric Administration (2012b) Tides and currents. http://tidesandcurrents.noaa.gov/ Accessed 15 July 2011. 
National Research Council, (1987) Responding to changes in Sea Level: Engineering Implications. National Academy Press: Washington, District Columbia.

Nicholls, R. and Cazenave, A. (2010). "Sea-Level Rise and Its Impact on Coastal Zones."

Science, 328(5985), 1517-1520.

Rahmstorf, S. (2007) “A semi-empirical approach to projecting future sea level rise" Science, (315), 368-370.

Ratcliff, J. and Smith, J. M. (2011) "Sea level rise impacts to military installations in lower Chesapeake Bay" Proc., Solutions to Coastal Disasters, ASCE, Reston, Virginia, 740-752 Resio, D. and J. Westerink (2008). "Modeling the physics of storm surges." Physics Today 61(9): 33-38.

Resio, D.; Boc, S.; Borgman, L.; Cardone, V.; Cox, A. et al. (2007) "White paper on Estimating Hurricane Inundation Probabilities" White paper published by the U.S. Army Corps of Engineers Coastal \& Hydraulics Laboratory, 125pp, Vicksburg, Mississippi.

Smith, J., Cialone, M., Wamsley, T., and McAlpin, T. (2010). "Potential impact of sea level rise on coastal surges in southeast Louisiana." Ocean Engineering, 37-47.

Thompson, E. F. and Cardone, V. J. (1996) Practical modeling of hurricane surface wind field. Journal of Waterway, Ports, Coastal and Ocean Engineering, 122(4), 195-205

Titus, J. G. (1990) “Greenhouse effect, sea level rise, and barrier islands: case study of. Long Beach Island, New Jersey". Coastal Management, (18)65-90.

Tremblay, T. A.; Vicent, J. S. and Calnan, T. R. (2008) Status and trends of inland wetland and aquatic habitats in the Corpus Christi Area. Final Report. Coastal Bend Bays and Estuaries Program, Texas General Land Office and National Oceanic and Atmospheric Administration. Austin, TX. 
Tsihrintzis, V., and Madiedo, E. (2000). "Hydraulic resistance determination in marsh wetlands." Water Resources Management, 285-309.

U. S. Army Corps of Engineers (2011) Sea level change considerations for civil works programs. Department of the Army, Washington, District of Columbia.

U. S. Geological Survey (2012) National Elevation Dataset. http://ned.usgs.gov/ Accessed 04 August 2011.

U.S. Fish and Wildlife Service (2012) The National Wetlands Inventory (NWI) http://www.fws.gov/wetlands/ Accessed 04 May 2011.

Wamsley, T.;Cialone, M.; Smith, J.M.; Ebersole, B.A. and Grzegorzewski, A. S. (2010). "The potential of wetlands in reducing storm surge." Ocean Engineering, 59-68.

Warner, N. N. and Tissot, P. E.(2012) "Storm flooding sensitivity to sea level rise for Galveston Bay, Texas" Ocean Engineering, (44), 23-32

Westerink, J., Luettich, R., Feyen, J., Atkinson, J., Dawson, C., Roberts, H., Powell, M., Dunion, J., Kubatko, E., and Pourtaheri, H. (2008). "A basin- to channel-scale unstructured grid hurricane storm surge model applied to southern Louisiana." Monthly Weather Review, 833-864.

Woodruff, J., D.; Irish, J., L.; Camargo, S., J. (2013) “Coastal flooding by tropical cyclones and sea-level rise" Nature (504)44-52

Zhang, K.; Li, Y.; Liu, H.; Xu, H. and Shen, J. (2013) Comparison of three methods for estimating the sea level rise effect on storm surge flooding. Climatic Change 118:487-500. 
Table 1: Meteorological parameters used to create the hypothetical storms.

\begin{tabular}{llll}
\hline Track & Radius to maximum & $\begin{array}{l}\text { Forward Speed } \\
(\mathrm{km} / \mathrm{h})\end{array}$ & $\begin{array}{l}\text { Central } \\
\text { Pressure(mb) }\end{array}$ \\
\hline wind $(\mathrm{km})$ & 31 & 11 & 960 \\
\hline A & 31 & 37 & 960 \\
\hline A & 31 & 37 & 930 \\
\hline B & 31 & 11 & 960 \\
\hline B & 31 & 37 & 960 \\
\hline B & 31 & 37 & 930 \\
\hline C & 31 & 11 & 960 \\
\hline C & 31 & 37 & 960 \\
\hline C & 31 & 37 & 930 \\
\hline
\end{tabular}


Figure 1: Upper panel: Location of the study area in the Gulf of Mexico; and Lower panel: Coastal bays under study and location of hurricane tracks landfall

Figure 2: Eustatic sea-level before model simulation using a 'bathtub' type model as base condition.

Figure 3: Upper panel: Flooded area extent by eustatic SLR affecting wetlands and other coastal vegetation. Middle panel) Mean Manning's $n$ variation due to SLR in the study area. Lower panel: Reduction in wind shielding by dense vegetation quantified in aerial extent as a result of SLR.

Figure 4: Geospatial impacts of SLR on frictional drag at sea bottom quantified by reduction in the Manning's $n$ values: a) $0.5 \mathrm{~m}$ of SLR; b) $1.0 \mathrm{~m}$ of SLR; c) $1.5 \mathrm{~m}$ of SLR; and d) $2.0 \mathrm{~m}$ of SLR.

Figure 5: Overall impact of sea-level rise on peak surge for the study region. Traced line shows the mean of 215 recording points and 9 storm conditions (Eq. 5). The circle dots indicate the mean of 215 locations for each storm condition (Eq. 7).

Figure 6: Left panel: Impact of land cover changes on peak surge. The lighter grey area indicates the surge response to land cover changes only (Eq. 5) and the darker grey indicates the contribution of geometry changes to the surge anomaly (Eq. 8). The dashed line indicates the resulting impact of sea-level rise on the surge anomaly neglecting land cover changes. Right 
panel: Average percent increase in peak surge due to changes in land cover by sea level rise in coastal bays. Lighter grey color indicates the standard deviation.

Figure 7: Effects of geographical location on the peak surge anomaly caused by land cover changes for Storm on track B, Vf: $37.0 \mathrm{~km} / \mathrm{h}$ and $C p: 930 \mathrm{mb}$. 


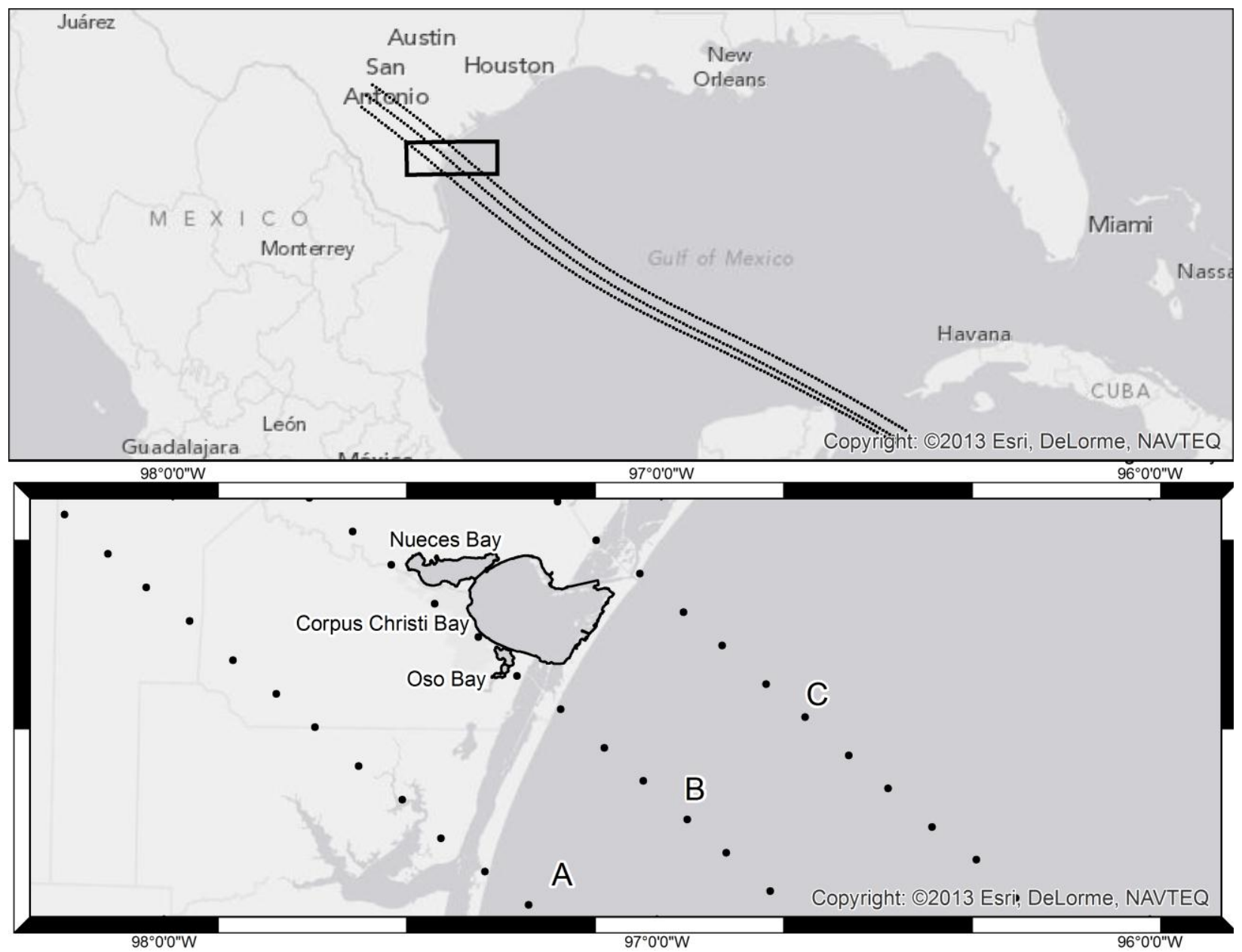


Case: SLR 0.5 meters

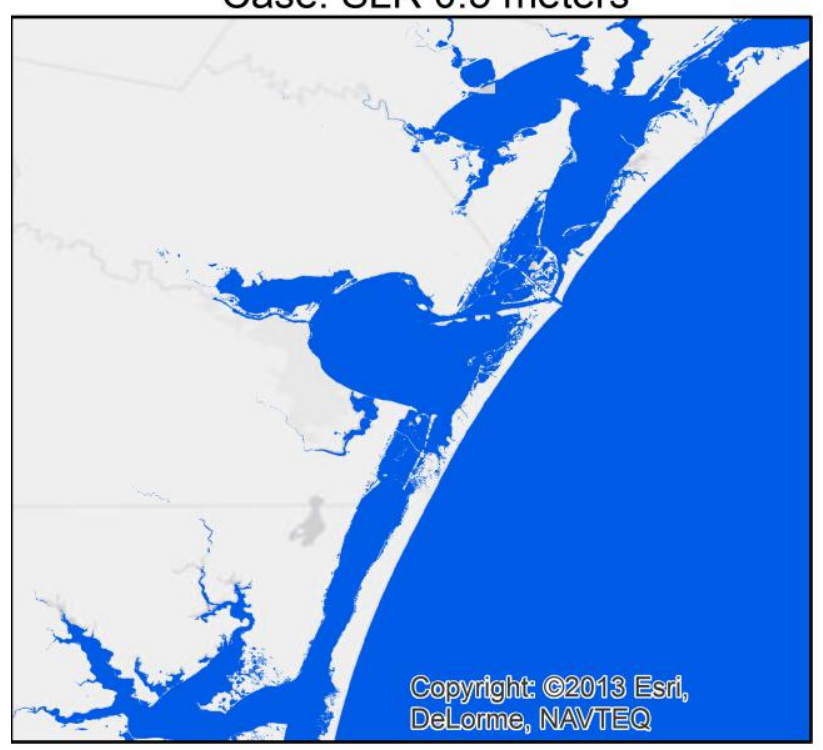

Case: SLR 1.5 meters

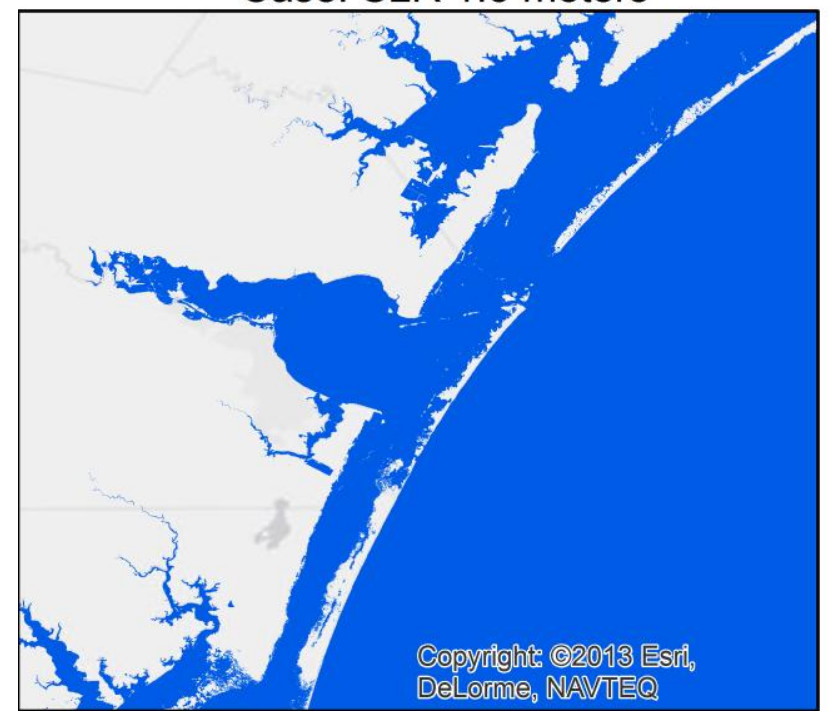

Case: SLR 1.0 meters

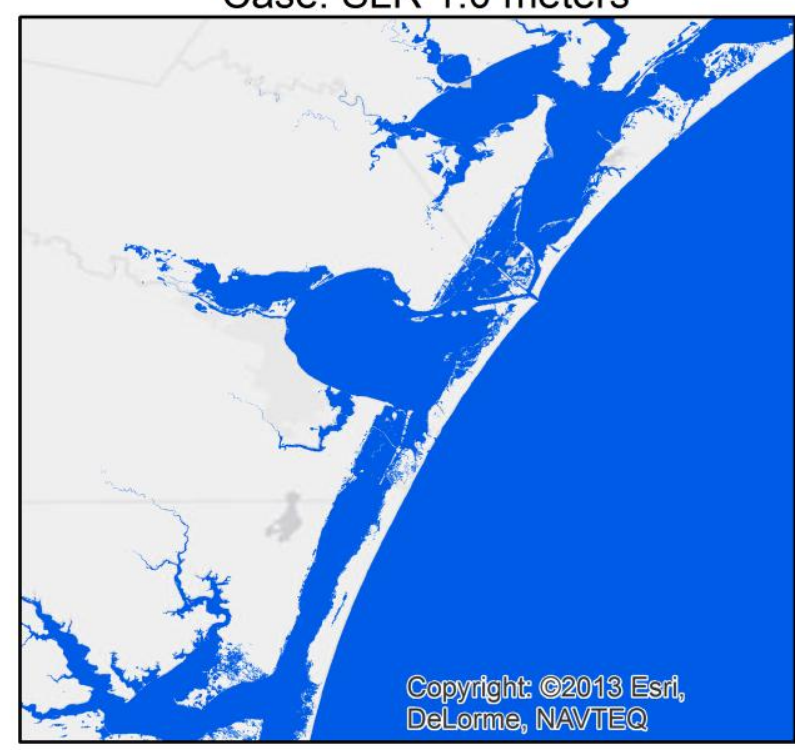

\section{Case: SLR 2.0 meters}

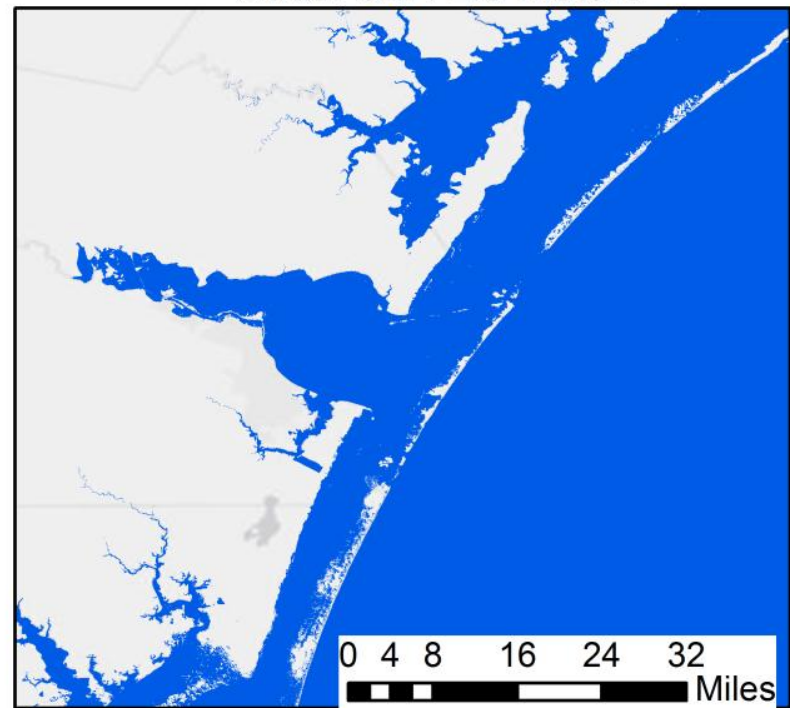




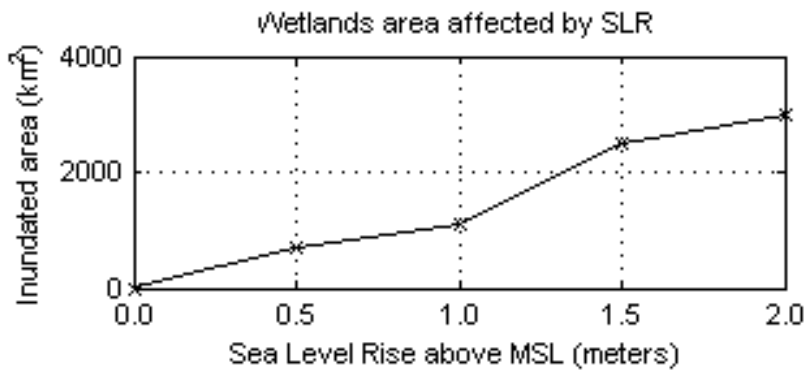

Mean bottom friction (Mannings $n$ ) variation with SLR

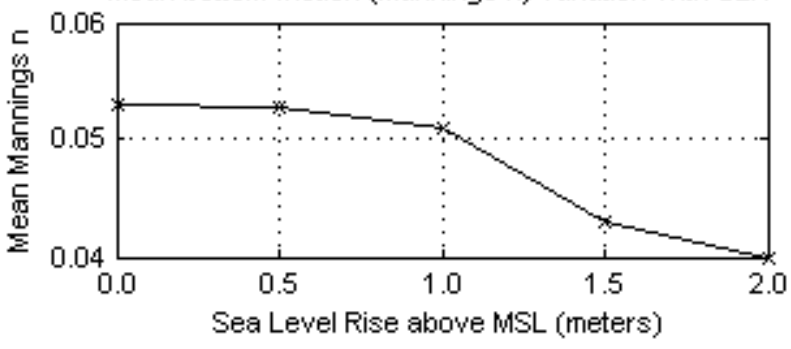

Reduction in wind shielding areas with SLR

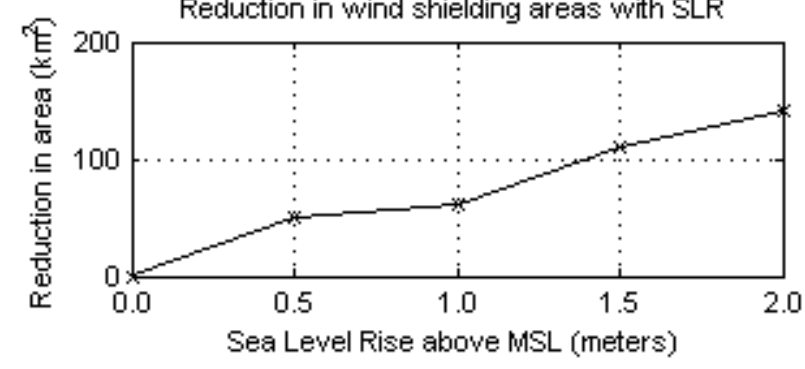


Case: SLR 0.5 meters

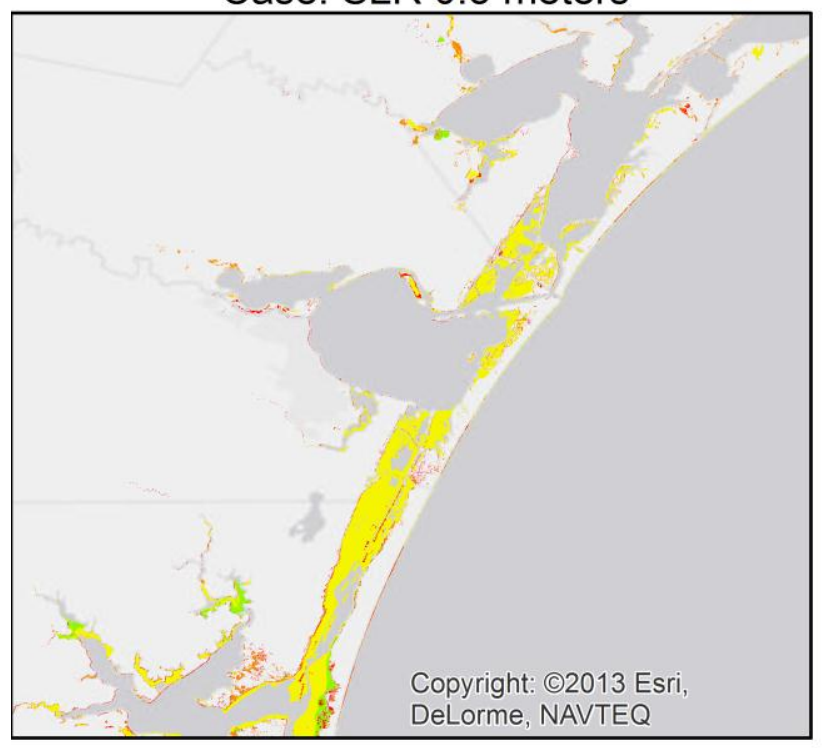

Case: SLR 1.5 meters

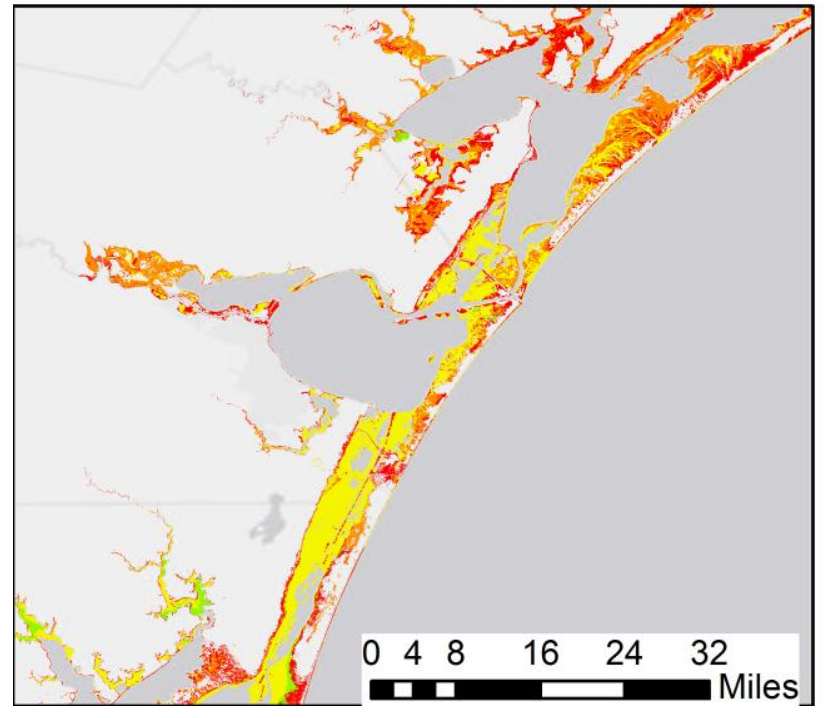

Case: SLR 1.0 meters

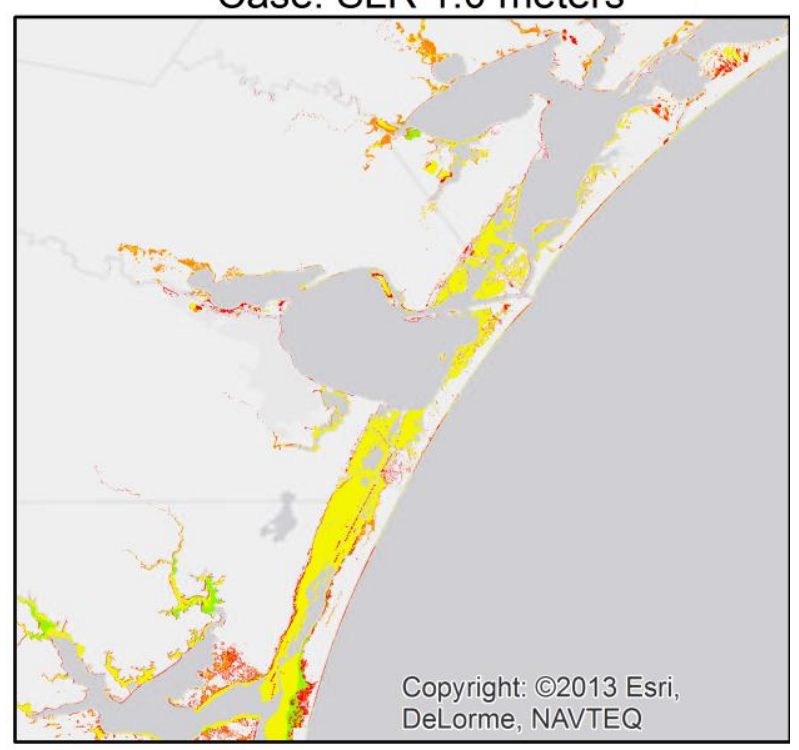

Case: SLR 2.0 meters

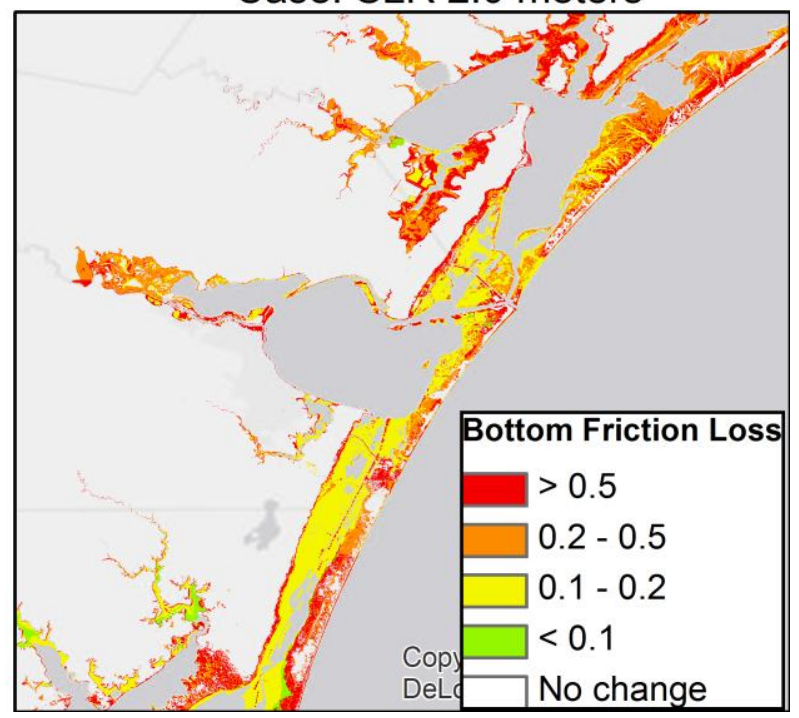




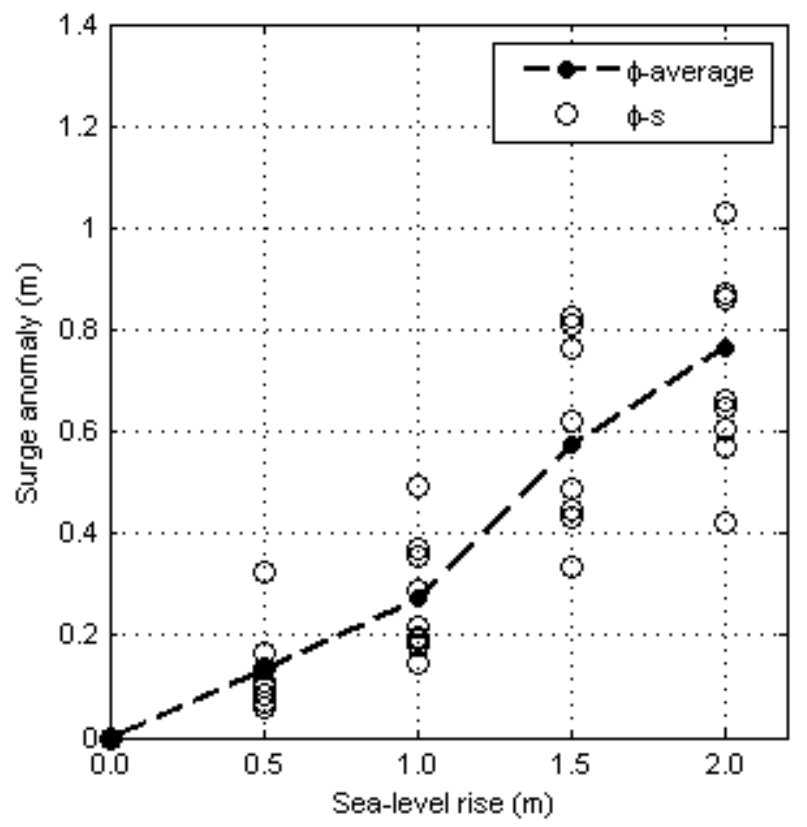



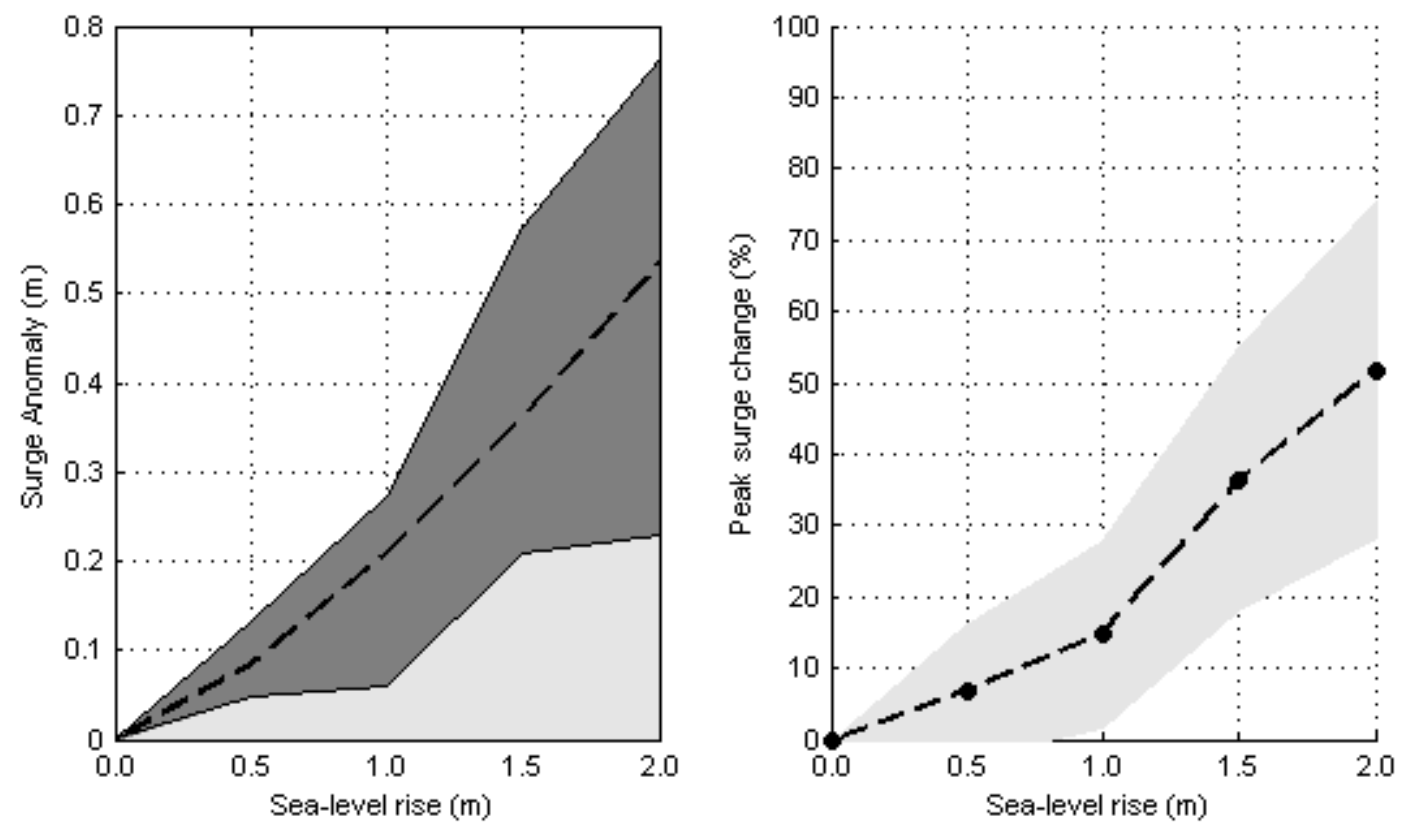
Case: SLR 0.5 meters

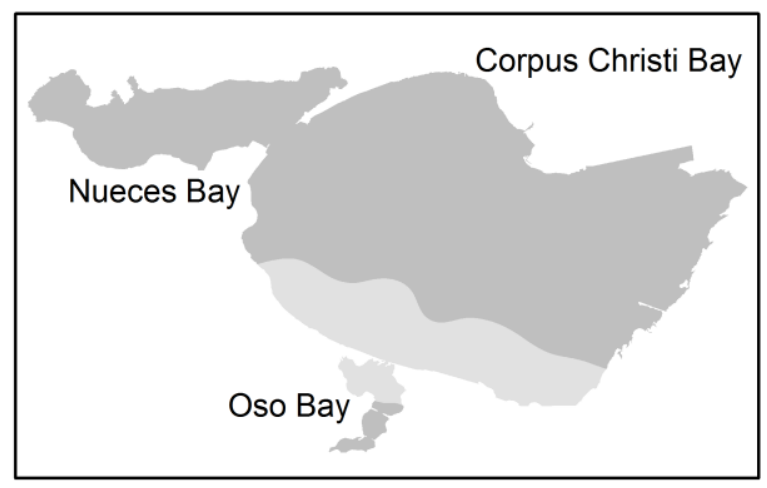

Case: SLR 1.5 meters

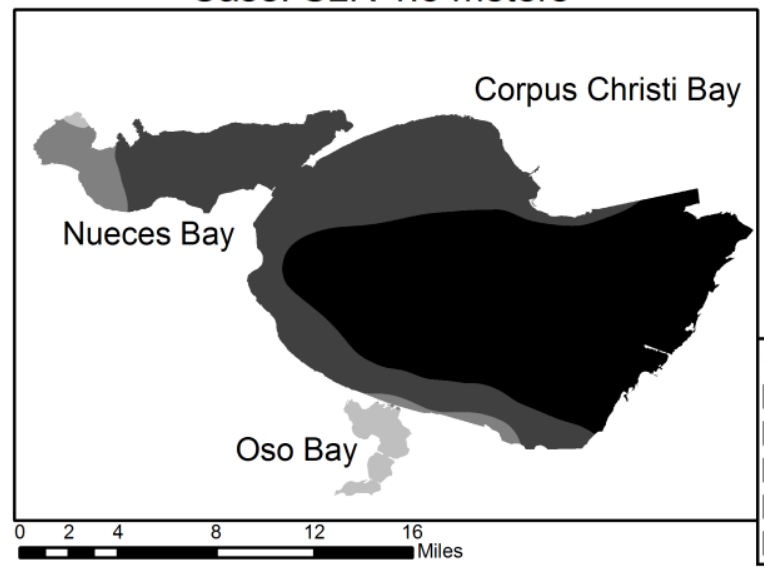

Case: SLR 1.0 meters

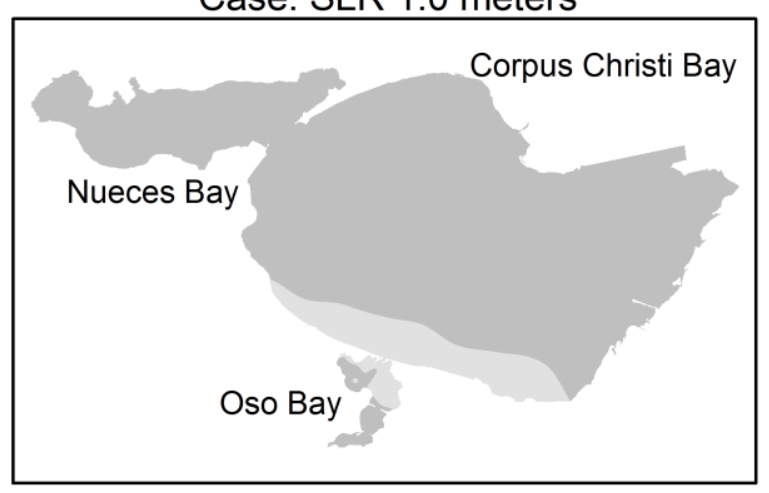

Case: SLR 2.0 meters

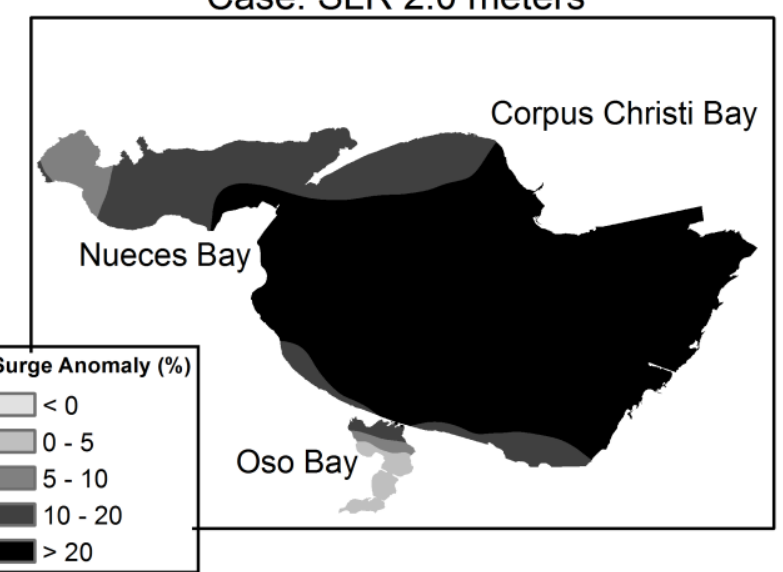

